\title{
BREVE HISTORIA CRÍTICA Y ANÁLISIS COMPARATIVO DE LAS POLÍTICAS APLICADAS EN EUROPA A LAS ÁREAS DE MONTAÑA'
}

\author{
Carmen Delgado Viñas \\ Departamento de Geografía, Urbanismo y Ordenación del Territorio \\ Universidad de Cantabria
}

\begin{abstract}
RESUMEN
En Europa parece que existe una gran distancia entre las declaraciones teóricas, la normativa legal y las actuaciones prácticas en relación con las políticas aplicadas a las áreas de montaña. La intención última de este artículo es realizar el contraste entre unas y otras y, en definitiva, contribuir a la reflexión colectiva y al debate sobre la conveniencia de las realizaciones pasadas y la exigencia de hacer realidad con urgencia nuevas formas de intervención.
\end{abstract}

Palabras clave: Áreas/Zonas de montaña, políticas europeas, políticas integradas, desarrollo sostenible, Unión Europea.

\section{ABSTRACT}

It seems that there is in Europe a great distance between the theoretical declarations, the legal norm and the practical performances in relation to the policies applied to the mountain areas. The final mission of this article is to make the contrast between and

1 Este estudio se enmarca en el trabajo que desde hace años viene realizando el Colectivo de Investigadores sobre las Montañas Españolas (CIMA) del que la autora forma parte. Está vinculado con el Proyecto de Investigación SEJ2004-08250-C02-01 GEOG (Plan Nacional I+D+I 2004-2007), realizado actualmente por un equipo de investigadores de las Universidades de Cantabria y Salamanca, del que la autora es investigadora principal. Así mismo, entronca con el proyecto estimulado por el Parlamento de Cantabria, en el ejercicio de su función institucional como Vicepresidente de la Asociación Europea de Regiones de Montaña y de coordinación de los grupos de trabajo de esta institución en las áreas de legislación e investigación, que se inició con el desarrollo de Cátedra Cantabria 2005 («La Montaña Cantábrica, una montaña viva»), cuya dirección se encargó a la autora, y que continúa con la cofinanciación de becas para realizar el estudio de la políticas y las legislaciones sobre zonas de montaña en Europa. Una versión previa y resumida de este artículo ha sido presentada como comunicación, bajo el título «Las políticas aplicadas en Europa a las áreas de montaña: una síntesis y algunas reflexiones», al XIII Coloquio de Geografía Rural de la AGE («Las agriculturas españolas y la política agraria comunitaria 20 años después»), celebrado en la Universidad Internacional de Andalucía, Baeza, del 4 al 6 de octubre de 2006. 
others, really, to contribute to the collective reflection and the debate on the convenience of the last accomplishments and the exigency of making reality with urgency new forms of intervention.

Key words: Areas/Zones of mountain, european policies, integrated policies, sustainable development, European Union.

«Las zonas de montaña en Europa son parte fundamental de su patrimonio natural y cultural, pero hoy se enfrentan con dificultades, como la lejanía y la falta de oportunidades económicas. Esta conferencia se propone explicar cómo la Unión Europea, al trabajar en colaboración con representantes de las zonas de montaña, puede contribuir a crear las condiciones de un desarrollo sostenible.»

Con estas palabras, el 17 de octubre de 2002, Romano Prodi, Presidente de la Comisión Europea, inauguraba la conferencia sobre «Las políticas comunitarias y la Montaña». Dicha conferencia, que resultó ser el principal acto con que la Unión Europea contribuyó a la celebración del Año Internacional de la Montaña, fue significativamente organizada de forma conjunta por Michel Barnier, Comisario responsable de la política regional y la reforma institucional, y Franz Fischler, Comisario responsable de agricultura. En ella participaron casi 400 delegados de la Unión Europea y de los países candidatos a la adhesión, miembros del Parlamento Europeo, del Comité Económico y Social y del Comité de las Regiones, con la intención de debatir la forma en que las políticas comunitarias podrían contribuir a crear nuevas oportunidades en las zonas de montaña.

El Comisario Michel Barnier insistió en la importancia que las áreas de montaña tienen para Europa: «Las zonas de montaña cubren cerca de una tercera parte del territorio de la Unión. Ninguna política europea de desarrollo territorial puede permitirse olvidar estas zonas y esta es la razón por la que, actualmente, un $95 \%$ de estas zonas está comprendido en la política de desarrollo regional de Europa. Ello ha contribuido a superar las dificultades naturales y a crear nuevas oportunidades para futuras generaciones».

¿Realmente es así? ¿Las políticas públicas aplicadas hasta ese momento en los países de la Unión Europea han ayudado a vencer algunas dificultades naturales? ¿Se han creado desde entonces nuevas oportunidades para los habitantes de nuestras montañas?

Soy consciente de que resultaría pretencioso, cuando menos, dar una respuesta tajante a las preguntas anteriores; más modestamente, con esta aportación me propongo hacer un sucinto repaso de las declaraciones teóricas y de las actuaciones prácticas en relación con las políticas aplicadas a las áreas de montaña, con la intención de contribuir a la reflexión colectiva sobre la pertinencia de las realizaciones pasadas y la exigencia de hacer realidad con urgencia nuevas formas de intervención.

Para ello, aunque sin propósito de exhaustividad, he considerado las políticas de montaña en un sentido amplio, de forma que se pueden incluir tanto las medidas y políticas generales, en relación con los aspectos fundamentales que atañen a las áreas de montaña y que tiene un impacto territorial directo sobre ellas, como las políticas sectoriales con efectos particulares sobre el desarrollo de zonas de montaña (agricultura, turismo, etc.), las acciones o programas que implican a zonas de montaña y, sobre todo, las medidas y políticas expresamente concebidas para responder a las necesidades específicas de zonas de montaña, las que podríamos conceptuar como políticas integradas de montaña. Y todo ello a diversas escalas: desde la comunitaria supraestatal a las regionales, pasando por la estatal. 


\section{Nuevas funciones, incipientes ventajas y riesgos inéditos de las áreas de montaña en el espacio europeo}

Las áreas de montaña son percibidas cada vez más como espacios de gran relevancia territorial, poseedores de una inconmensurable riqueza ecológica y patrimonial, en especial paisajística, pero afectados también por una problemática socioeconómica muy amplia, que procede no sólo de las limitaciones inherentes a las características de su medio natural sino, sobre todo, de las dificultades generadas recientemente por su integración en el contexto económico actual y su articulación en los diferentes marcos territoriales ${ }^{2}$.

Porque a nadie se le oculta que las áreas de montaña europeas, en mayor medida aún que otros espacios rurales, han sufrido durante el último siglo intensos procesos de deslocalización de sus actividades económicas y de su población. Procesos que se han manifestado en las últimas décadas, en el seno de la economía capitalista neoindustrial, en una profunda regresión que algunos autores concretan en «el despoblamiento, la explotación irracional de pastos y bosques, el desarrollo salvaje del turismo, la contaminación atmosférica generalizada, la construcción de infraestructuras de comunicación y la intensificación de las extracciones de minerales a cielo abierto» (Mairal Lacoma, 1993,16).

Sin llegar a tales extremos en algunos casos, lo cierto es que las áreas de montaña, en general, siguen atravesando una situación de crisis. Bien es verdad que algunas de ellas han logrado dinamizar su base económica a través del desarrollo de las actividades turísticas, recreativas y de ocio, lo que no es óbice para que, incluso en estas ocasiones, algunos de los otros elementos que caracterizaban antes a estos espacios, tanto desde una perspectiva natural como humana, se encuentren en proceso de deterioro y declive. Es lo que sucede con la agricultura y la ganadería de montaña, las actividades que más han contribuido a esculpir los paisajes actuales y a mantener la biodiversidad. Al mismo tiempo que continúa la pérdida de población residente habitual, la simplificación económica y el empobrecimiento cultural y medioambiental.

El patrimonio territorial, reflejado a través de los paisajes naturales humanizados, y los productos de alta calidad son los pilares sobre los que se asienta la creciente y reciente revalorización de las áreas de montaña y la adquisición de nuevas funciones socioespaciales, entre las que cabe resaltar las relacionadas con los flamantes usos vinculados con el sector servicios y con los aprovechamientos estratégicos colectivos.

A fomentar estos usos se orientan diversas formas de intervención sobre las áreas de montaña que giran en torno a tres ejes interrelacionados: la conservación del medio natural, la explotación de los recursos patrimoniales y paisajísticos y la promoción del turismo rural.

Si bien unos y otras representan un gran potencial y ofrecen nuevas oportunidades para las áreas montañosas, en ningún caso están exentos de riesgos y contradicciones.

Los nuevos riesgos derivan de la posibilidad de conversión de las áreas de montaña en espacios de recreación musealizados e inertes para uso exclusivo de las sociedades urbanas,

2 «las cadenas de montañas ya no constituyen hoy en día barreras físicas, económicas o culturales. En parte, se han convertido incluso en espacios privilegiados de desarrollo residencial, económico y turístico. El desarrollo territorial se enfrenta así a los conflictos derivados de los distintos usos presentes en estos espacios... No sólo son espacios naturales de gran importancia, sino también espacios económicos indispensables para la vida. Muchas zonas de montaña de la UE se ven amenazadas por el desarrollo del turismo de masas, la construcción de presas y nuevas vías de transporte, así como por el sobrepastoreo, la erosión y el abandono de las explotaciones». Estrategia Territorial Europea (ETE, Hacia un desarrollo equilibrado y sostenible del territorio de la UE. Acordada en la reunión informal de Ministros responsables de ordenación del territorio en Potsdam, mayo de 1999 Publicada por la Comisión Europea, pp. 60 y 78). 
de la continuación de la explotación de recursos, incluso la sobreexplotación, de acuerdo con intereses ajenos a la propia población montañesa, o del abandono material de las áreas que no sirven a estos designios. Tales riesgos han sido puestos de manifiesto por el Comité Económico y Social de la Unión Europea en su Dictamen sobre «El futuro de las zonas de montaña en la Unión Europea» que analizaré más adelante.

En realidad, las áreas de montaña europeas se encuentran inmersas hoy en una situación compleja y contradictoria que oscila entre la valorización medioambiental y la marginalización económica, la potenciación de la función residencial secundaria para los habitantes de las ciudades y la pérdida de la propia población, la apreciación creciente de la importancia estratégica de la conservación de sus recursos frente a limitación del aprovechamiento de esos mismos recursos para regenerar el propio tejido socioeconómico.

Por ello, con cierta frecuencia empieza a afirmarse que muchas de las oportunidades actuales de las áreas de montaña no parecen traducirse en oportunidades para el desarrollo sostenible de la propia sociedad montañesa y que la gestión sostenible de los recursos de la montaña no coincide en algunas ocasiones con el desarrollo sostenible del territorio montañés.

Valgan estos breves apuntes para recordar e insistir en que las áreas de montaña se encuentran entre los territorios en los que, en mayor medida, convergen conflictos derivados de la necesidad de conciliar aspectos tan diversos como la conservación de los ecosistemas y paisajes, las actividades de aprovechamiento, uso y gestión de los recursos naturales, el crecimiento económico y la mejora de la calidad de vida de las poblaciones que allí habitan de forma permanente; en definitiva, la exigencia de suscitar un desarrollo sostenible a través de la aplicación de las políticas pertinentes para estimularlo. Con esta problemática, resulta más que evidente que las zonas de montaña requieren políticas de desarrollo que no pueden reducirse a la aplicación de medidas generales y sectoriales, sino que tienen que ser específicas e integradas.

Por todo ello no debe extrañar que, al menos en teoría, las áreas de montaña hayan merecido una especial consideración por parte de la Unión Europea en conjunto y de los Estados miembros en particular.

En primer lugar porque parece universalmente aceptado que las zonas de montaña son muy valiosas y deben ser protegidas prestando atención principalmente a su desarrollo económico y a la salvaguardia de su entorno natural.

Por si ello no fuera suficiente, en segundo lugar, por una razón meramente cuantitativa, porque las zonas de montaña representan aproximadamente el $40 \%$ de la superficie de la UE y porque en ellas viven 66,8 millones de personas, que equivalen más o menos al 17,8 $\%$ de la población total de la $\mathrm{UE}^{3}$.

Desde esta perspectiva, la preocupación a escala comunitaria parece haberse acrecentado en los últimos años ante el hecho de que varios de los países integrados en la postrera ampliación poseen extensas áreas de montaña muy pobladas (Bulgaria, Polonia, la República Checa, Rumania, Eslovaquia y Eslovenia) y, por otra parte, en el caso de los Estados pertenecientes a la UE con anterioridad, porque las orientaciones presupuestarias a partir de 2007 podrían reducir drásticamente el importe de la financiación comunitaria con que atender a sus propios espacios de montaña.

3 Existen, no obstante, grandes diferencias entre unos y otros países europeos: los valores más altos corresponden a Austria y Grecia con $73 \%$ y $78 \%$ respectivamente mientras que Dinamarca y Países Bajos carecen de zonas de montaña. En el caso español las áreas de montaña ocupan algo más de $190.000 \mathrm{~km}^{2}$ que representan casi el $38 \%$ del territorio y en ellas habitaban más de 4.500 .000 personas en 2001 (algo más del $11 \%$ de la población censada en ese año). 


\section{Una preocupación creciente a nivel teórico, programático y declaratorio}

El interés por la problemática de las áreas de montaña ha estado ligado desde el principio a la política regional, incluso antes de que ésta quedara implementada como tal.

Las primeras manifestaciones de esas preocupaciones se pueden encontrar en la Recomendación 517 realizada en 1968 por la Asamblea Parlamentaria del Consejo de Europa en la que solicita a los gobiernos la definición de criterios para delimitar las regiones montañosas y el establecimiento de formas de cooperación internacional ${ }^{4}$. Como complemento de ésta, la Recomendación 570 de 1974 insiste en las nuevas funciones atribuidas a las áreas de montaña, en la ordenación del territorio europeo, en este caso en relación con el Arco Alpino, como espacios de ocio, nudos de comunicaciones y zonas de regeneración de los recursos naturales. A estos documentos se deben añadir, por su valor como precedentes, las continuas Declaraciones que emanan del Comité de Ministros del Consejo de Europa a partir de 1974, en particular la «Carta Ecológica de las Áreas de Montaña» de 1976.

La que podemos considerar como una segunda etapa se inicia con el Dictamen del Consejo Económico y Social de 28 de abril de 1988 sobre «Una política para las zonas de montaña», que responde a una nueva lógica territorial y a una filosofía multisectorial del desarrollo rural a partir del reconocimiento de las diferencias existentes en el espacio rural y, por lo tanto, de la necesidad de diseñar políticas y programas específicos para cada ámbito.

Pocos años más tarde es el Comité de las Regiones la institución que hace suyas, de manera prioritaria, las preocupaciones por el desarrollo de las áreas de montaña. Y lo hace con la aprobación, el 21 de abril de 1995, de un dictamen sobre el proyecto de «Carta europea de regiones de montaña $»^{5}$, uno de los documentos que se considera fundamental en el armazón teórico de la política europea para los espacios de montaña.

En él se insta a la Unión Europea a que se adhiera a dicha Carta considerando la importancia geográfica y demográfica dentro de Europa de las áreas de montaña, las funciones de interés general que desempeñan, especialmente en el ámbito del medio ambiente y en los sectores económico, social y cultural, el patrimonio excepcional representado por las zonas de montaña europeas, que debe valorarse y salvaguardarse, y cuya diversidad, identidad social, tradiciones y cultura deben defenderse y conservarse, la especificidad de su situación con respecto a las demás regiones de la Comunidad y de sus problemas económicos y sociales, pese a su diversidad, derivados de sus características ecológicas particulares, etc.

Resulta especialmente expresivo, asimismo, que, con un enfoque global para los problemas de la montaña, en dicho documento se inste «a que se ponga en práctica una política específica de desarrollo y protección para estas regiones, basada en el reconocimiento de su especificidad...» ${ }^{6}$.

4 Un repertorio exhaustivo de la normativa europea, comunitaria, estatal y regional, sobre las áreas de montaña puede encontrarse en CIMA (2005): Las Montañas Españolas: Territorio, Sociedad, Patrimonio y Cultura. Ministerio de Ciencia y Tecnología, http://www.lasmontanasespanolas.com/ y http://www.ub.edu/montesp/.

5 Dictamen del Comité de las Regiones sobre la Carta Europea de Regiones de montaña CDR 142/95. Diario Oficial $n^{\circ} \mathrm{C} 100$ de 02/04/1996 p. 0022

6 Como principios y objetivos fundamentales se marcan los siguientes:

- «alcanzar un equilibrio entre el nivel y calidad de vida de las poblaciones de las regiones de montaña y las de las demás regiones, respetando su diversidad,

- integrar todos los problemas económicos, sociales, culturales y medioambientales en una política de desarrollo duradero y de ordenación del territorio, aplicada mediante planes globales de ordenación, desarrollo y protección que permitan la integración y estrecha coordinación de las políticas y medidas en territorios homogéneos ...

- tener en cuenta y reconocer la unidad geográfica de cada zona de montaña, introduciendo el concepto de macizo montañoso como marco operativo para la aplicación de esta política». 
El documento es, a la vez, una llamada de atención sobre la evolución de las zonas de montaña al reconocer que es «sumamente preocupante» a pesar de las políticas desarrolladas hasta el momento por la Comunidad y la Unión Europea, de la creación de los fondos socioestructurales y de la aplicación de programas de iniciativa comunitaria?.

La escasa eficacia de las intervenciones es achacada, entre otras causas, a la falta de reconocimiento del carácter específico de las áreas de montaña, equiparadas hasta ese momento, con otras zonas desfavorecidas, y a la ausencia del establecimiento de objetivos propios, a pesar de las recomendaciones realizadas por «el Parlamento Europeo en su Resolución del 27 de mayo de 1987 y el Comité Económico y Social en su dictamen del 28 de abril de 1988, dado que ambas instituciones desean un enfoque global para los problemas de montaña».

En consecuencia, se urge a la obtención de «un equilibrio entre desarrollo y protección» y a la definición inmediata de «una política de las zonas de montaña». Peticiones que no han encontrado respuesta práctica hasta el día de hoy ${ }^{8}$.

Los siguientes dictámenes del Consejo Económico y Social siguen fielmente las directrices establecidas en la «Carta europea de regiones de montaña», como hace el de 25 de abril de 1996 sobre «El Arco Alpino: una oportunidad de desarrollo e integración».

Similar sentido tiene el dictamen aprobado el 18 de de septiembre de 1997 por el Comité de las Regiones titulado «Una política para la agricultura de montaña en Europa», en el que preconiza la definición de una política transfronteriza de las zonas de montaña, incluyendo una política específica en el ámbito de la agricultura, debido a la contribución de esta última al mantenimiento de las poblaciones en estas zonas, así como un tratamiento privilegiado en la asignación de los derechos de producción y cuotas lecheras. Recomienda también introducir un sistema suplementario de complemento de los ingresos, adoptar un marco legal global en favor de productos alimenticios de montaña, garantizar una política activa de empleo de los jóvenes agricultores, promover la lucha contra la tala de árboles y la conservación del medio ambiente así como proteger el patrimonio cultural.

Poco más tarde, en octubre de 1998, es la Comisión de Agricultura y Desarrollo Rural la que emite un informe sobre «Una nueva estrategia para las zonas de montaña», realizado sobre la base del estudio previo de la Dirección General de Estudios del Parlamento Europeo titulado «Hacia una política europea de las montañas» en el que se instaba a la Comisión a reforzar las medidas existentes en favor de las zonas de montaña, las zonas desfavorecidas y las zonas ecológicamente sensibles en cooperación con las regiones y gobiernos afectados.

Con motivo de la declaración del Año Internacional de la Montaña por decisión de la Asamblea General de la ONU, el Comité Económico y Social Europeo, así como el Parlamento Europeo y el Comité de las Regiones, volvieron a manifestar un interés renovado por

7 El dictamen llega a afirmar que «las tendencias (regresivas) mencionadas anteriormente no sólo no se han invertido sino que, por el contrario, en muchas regiones de montaña, parecen haber cobrado mayor amplitud, aumentando las desigualdades entre regiones y cuestionando el objetivo de cohesión económica y social y de reducción de las diferencias de desarrollo entre las regiones, al contrario de lo dispuesto en los artículos 2 y $130 \mathrm{~A}$ del Tratado de la Unión Europea, la vez que representan una amenaza para la protección del medio ambiente».

$8 \mathrm{Ni}$ siquiera se logró la aprobación de la propia «Carta europea de regiones de montaña» a pesar de que el Congreso de Poderes Locales y Regionales del Consejo de Europa continuó la iniciativa, aprobando, en mayo de 2000, la Recomendación 75 (2000) sobre adopción de un borrador de Convención de Regiones de Montaña y, posteriormente, amparándose en el Año Internacional de la Montaña, otra Recomendación CG (10) 9, sobre la Carta Europea de la Montaña, la cual fue aprobada finalmente por el Comité de Ministros el 25 de abril de 2003. En ella se recomienda a los Estados Miembros: adaptar su legislación y sus prácticas, tanto dentro del marco nacional como en el pleno de la Unión Europea, conforme a los textos de la Carta Europea de la Montaña y promover la cooperación entre colectivos territoriales dentro de las zonas de montaña (Fernández Arroyo, 2005). 
que la Unión Europea reconociese las características específicas de las zonas de montaña y les aplicase una política transversal adaptada. Por tanto, y de forma casi simultánea, en 2002 se hicieron públicos el informe del Comité de las Regiones de la Unión Europea sobre las «Medidas comunitarias a favor de las zonas de montaña» y la declaración de la Asociación de Autoridades Políticas de Regiones de Montaña (AEM) ${ }^{10}$.

En el primer documento mencionado, el Comité de las Regiones señala que es necesario consagrar jurídicamente la especificidad de las zonas de montaña y establecer una normativa europea que tenga como finalidad la reducción de las desventajas económicas y estructurales de dichas zonas. Se considera imprescindible compensar con ayudas las desventajas naturales permanentes y dotar de forma adecuada a las zonas de montaña con instrumentos de política estructural para superar las desventajas no permanentes.

Por las mismas fechas, y coincidiendo con el veinticinco aniversario de la aplicación de la primera legislación de la Comunidad sobre Agricultura de Montaña (Directiva 75/268/ CEE), el Parlamento Europeo instó a la Comisión a que sometiera al propio Parlamento y al Consejo, en el año 2001, una comunicación en la que se expusieran las acciones que se iban a realizar al año siguiente con motivo del Año Internacional de la Montaña. Igualmente se instó a elaborar un plan de desarrollo sostenible de las regiones de montaña de la Unión Europea y de los Estados candidatos a la adhesión.

En relación con esas demandas, el Consejo Económico y Social de la Unión Europea emitió en julio de 2002 un nuevo dictamen sobre «El Futuro de las Zonas de Montaña en la Unión Europea» que, diseñado a partir del balance de la acción comunitaria en relación con las zonas de montaña, puede ser considerado como un auténtico programa de la dirección que se pretende seguir a partir de dos principios fundamentales: la integración de las zonas de montaña en la futura política de los Fondos Estructurales y la formulación de una política de la montaña que sirva de modelo de desarrollo sostenible y equitativo ${ }^{11}$.

El documento hace hincapié en la existencia en las áreas de montaña de algunas desventajas, viejas y recientes, permanentes y superables, pero también reconoce la presencia de muchos aspectos favorables. Entre ellos se explicitan los problemas demográficos ${ }^{12}$, dotacionales e infraestructurales ${ }^{13}$, los derivados de las nuevas actividades

9 Informe del Comité de las Regiones sobre el tema «Medidas comunitarias en favor de las zonas de montaña» (2003/C 128/05) Diario Oficial $n^{\circ}$ C 128 de 29/05/2003 p. 0025 - 0040. En el informe se pide a la Comisión que elabore una definición clara de zona de montaña y que éstas se incluyan el Tratado Constitucional junto a las «regiones o islas menos favorecidas, incluidas las zonas rurales», en la medida en que precisan una atención especial a la hora de mejorar la cohesión económica, social y territorial.

10 La AEM también propugna la elaboración y puesta en práctica, a nivel paneuropeo, comunitario, nacional y regional, de una política de desarrollo sostenible en las zonas de montaña. Esta política, por ser global, integrada y equilibrada, deberá tener en cuenta la ordenación del territorio, el desarrollo económico, el progreso social, las identidades culturales, la gestión y la protección de los recursos naturales, la biodiversidad y el medio ambiente.

11 Dictamen del Comité Económico y Social sobre «El futuro de las zonas de montaña en la Unión Europea» (2003/C 61/19). 14.3.2003 ES Diario Oficial de la Unión Europea C 61/113.

12 «la estructura demográfica de las zonas de montaña es generalmente vulnerable (baja densidad de población y envejecimiento debido al éxodo de las jóvenes generaciones y/o la instalación de jubilados), en particular en los países de montaña candidatos a la adhesión»

13 «En las zonas de montaña, las infraestructuras y las redes de comunicación representan un elemento fundamental, en la medida en que el aislamiento constituye un freno importante a la competitividad y que el creciente volumen de transporte intracomunitario de mercancías se traduce en una presión sobre los macizos atravesados y su población que es conveniente controlar y compensar». «En lo que atañe a las nuevas tecnologías de la información y la comunicación (NTIC), su accesibilidad en montaña constituye una baza primordial. Los importantes costes adicionales derivados de las dificultades técnicas que plantea el relieve (obstáculos a la propagación de las ondas, largas distancias) constituyen una verdadera amenaza de fractura territorial para las zonas de montaña, en comparación con los demás territorios» 
turísticas ${ }^{14}$ y de los aprovechamientos agrarios ${ }^{15}$, del abastecimiento de recursos hídricos y la producción energética ${ }^{16}$, la urbanización, la construcción y la función residencial secundaria ${ }^{17}$.

Se concibe así a las áreas de montaña europeas en la actualidad como espacios plurifuncionales en los que los usos y aprovechamientos recientes despiertan grandes expectativas, pero también representan elevados riesgos potenciales: «la economía de los territorios de montaña se caracteriza por un buen número de bazas, pero también de puntos débiles, por lo que requiere un tratamiento específico ... los territorios de montaña se caracterizan ante todo por una fuerte desventaja geofísica derivada de la inclinación del terreno, la altitud y el clima, pero también por su situación generalmente aislada, así como por la riqueza de su patrimonio y de sus recursos naturales, tan excepcionales como frágiles. Lo que está en juego en estos territorios es algo insustituible, por lo que es imprescindible una política pública para contenerla especulación excesiva de que podrían ser objeto» (el subrayado es mío).

Por ello se recomienda la creación de un Observatorio Europeo de la Montaña, sobre la base de la distribución en zonas de los municipios de montaña, para que se tomen en consideración no sólo las desventajas naturales, sino también las socioeconómicas. Añade que las zonas de montaña requieren una política dirigida a reducir físicamente sus obstáculos más que acciones compensatorias de las rentas. Para ello, deben realizarse políticas activas sobre infraestructuras y comunicación que equiparen las oportunidades de su población con la de otros territorios, permitiendo que los servicios de comunicaciones locales puedan conectarse con los grandes ejes de circulación intracomunitaria y/o con las redes de alto rendimiento, cobertura de telefonía móvil y acceso a banda ancha.

Siguiendo con las actuaciones iniciadas en este sentido, la Comisión Europea ha publicado recientemente un informe sobre las áreas de montaña en los Estados miembros de la Unión Europea, en los países que van a acceder a ella y en otros países, que concluye con la necesidad de disponer de buena información para la toma de decisiones y de evaluar

14 «Si bien la montaña tiene una indudable vocación turística, es preciso canalizar este tipo de desarrollo para procurar integrarlo en una lógica de desarrollo sostenible. Esta consideración es especialmente pertinente para los futuros países miembros de Europa Central y Oriental, en los que aún queda por desarrollar lo esencial del potencial turístico de las zonas de montaña. Al igual que para la agricultura, el turismo no puede por sí solo constituir el fundamento de la economía de estas zonas, que tiene que caracterizarse por su diversidad En este sentido, y dentro de los límites que imponen los principios del desarrollo sostenible, es imprescindible diversificar la oferta turística de las zonas de montaña con el fin de lograr una mejor distribución, tanto en el tiempo (mayor equilibrio de la frecuentación turística entre las distintas temporadas) como en el espacio (mejor distribución de los flujos turísticos en el territorio)»

15 «Porque constituye un pilar fundamental de la economía de las zonas de montaña y, sobre todo, una actividad esencial e insustituible para el indispensable mantenimiento de estas zonas, y porque contribuye a la producción de productos agrícolas y agroalimentarios de calidad, la agricultura de montaña debe ser objeto de un enfoque adaptado por parte de la política agrícola común, con el fin de garantizar su anclaje en los territorios de montaña».

16 «La montaña es una gran productora de recursos hídricos, tanto en cantidad como en calidad, y desempeña a este respecto una función territorial esencial que constituye un servicio de interés colectivo cuyas obligaciones inherentes deben compensarse.». «el fuerte potencial de las zonas de montaña respecto a la energía eólica debe ser objeto de un desarrollo controlado, para evitar una degradación global de la calidad paisajística de las regiones de montaña».

17 «El urbanismo en las zonas de montaña tiene un carácter muy específico. La gestión de un patrimonio arquitectónico vivo no sólo requiere que se brinden posibilidades de construcción sino también que no se abandone el patrimonio existente. Tampoco debe ponerse en peligro la integridad de los paisajes y espacios naturales dignos de atención, y la construcción de residencias secundarias no debe conducir a la desvitalización del hábitat permanente de las zonas de montaña. Por lo tanto, se debe adoptar un planteamiento específico dirigido a los propietarios de estas residencias, con el fin de integrarlos en la vida local». 
las políticas aplicadas con vistas a preparar la próxima programación de fondos europeos (Nordregio, 2004).

Algunas de las actividades programáticas comunitarias han tenido correspondencia a escala estatal, generalmente con los mismos escasos resultados prácticos; sirva como ejemplo lo ocurrido en España con el proyecto de Carta de las Montañas.

El Consejo de Ministros español, haciéndose eco de la Resolución de las Naciones Unidas y de las iniciativas comunitarias citadas, instituyó en marzo de 2000 el Comité Español para el Año Internacional de la Montaña. A propuesta del Ministerio de Medio Ambiente, al que estaba adscrito a través de la Secretaría General de Medio Ambiente, este Comité acordó elaborar una Carta de las Montañas cuya orientación fue marcada por las recomendaciones del Seminario sobre Conservación y Desarrollo Sostenible en Áreas de Montaña, celebrado en Valsaín en febrero de 2002 bajo el auspicio del Comité.

Cuatro años después, a mediados de 2006, la Carta Española de las Montañas continúa siendo un mero borrador pese, incluso, a que en mayo de 2005 el Congreso de los Diputados aprobó dos proposiciones No de Ley instando a agilizar su aprobación y a la elaboración de un «programa de promoción, apoyo, medidas económicas y de sensibilización en el ámbito de la Carta de las Montañas» (Fernández Arroyo, 2005).

En estos momentos, entre otras acciones, el gobierno francés, en colaboración con la FAO y bajo el alto patrocinio del Presidente de la República Francesa, ha organizado una Conferencia Ministerial Internacional sobre el Futuro de la Montaña, que tendrá lugar en Chamonix, Francia, entre el 9 y el 11 de diciembre de 2006. Su finalidad es reanudar, cuatro años después del Año Internacional de la Montaña, una verdadera dinámica internacional para el desarrollo voluntario, justo y sostenible de los territorios de montaña; habrá que confiar en que se obtengan mejores resultados ${ }^{18}$.

Resulta elocuente que la convocatoria de esta Conferencia se vuelva a replantear los tres grandes objetivos que fueron identificados en las principales recomendaciones del informe-balance del Año Internacional de la Montaña: conocer la montaña, actuar en la montaña y vivir en la montaña.

Centrándonos en el segundo objetivo, estrechamente vinculado al asunto tratado en este trabajo, parece conveniente resaltar que la actuación sobre las áreas de montaña se entiende en un triple sentido:

- identificar «las condiciones y medios de vida sostenible para el mantenimiento de las poblaciones en zonas de montaña y la gestión colectiva de los territorios»

- establecer «políticas diferenciadas» contemplando también las expectativas de las poblaciones que no viven en las áreas de montaña e

- implantar «políticas transversales mediante programas de apoyo a los actores de las zonas de montaña adaptados al conjunto de los problemas de sus territorios»

Desde una perspectiva programática parece que las instituciones europeas, comunitarias y estatales, desde hace treinta años tienen las ideas claras en relación con las necesidades de las áreas de montaña y con las posibles formas de actuación sobre ellas. Sin embargo, a lo largo de ese tiempo apenas se ha «traspasado la frontera de lo académico y/o declarativo

18 En la propia convocatoria del evento se afirma que «El Año Internacional de la Montaña había contribuido enérgicamente a la concienciación de estos problemas estructurales. Pero, debido a la carencia de verdaderas instancias operacionales de conocimiento, de concertación, de decisión y de financiación a escala nacional, regional e internacional, las herramientas creadas se han revelado ineficaces.» 
para convertirse en el sustrato de una legislación ad hoc» (García Pascual, 2006,171). No parece haber sido por falta de argumentación programática y armazón teórica.

\section{Unas actuaciones prácticas dispersas y mal adaptadas a la realidad actual de las áreas de montaña y a las propias declaraciones de las instituciones europeas}

En absoluta contradicción con las declaraciones programáticas, y a pesar de ser un problema común a la mayoría de los países miembros, no ha existido ni existe en la UE una política específica e integrada para las zonas de montaña a ninguna de las escalas espaciales contempladas.

Las acciones sobre estos territorios se enmarcan en políticas más generales como la Política Agraria Común y la Política Regional, especialmente la primera, que es la que ha tenido mayor incidencia sobre las áreas de montaña hasta el momento. Así lo afirma de forma tajante el dictamen de 2003 del CES sobre «El futuro de las Zonas de Montaña de la Unión Europea» ${ }^{19}$.

Tanto a nivel general, comunitario, como estatal y regional, son las políticas y medidas de carácter sectorial las que han tenido, y siguen teniendo, primacía absoluta entre las que afectan directa e indirectamente a los espacios de montaña.

Por otra parte, la práctica totalidad de las políticas dirigidas a estas áreas se siguen centrando en el aprovechamiento agrario, en discrepancia también con el discurso oficial en voga, en el que se insiste en el carácter multifuncional de estas áreas (nuevas funciones socioeconómicas, culturales y medioambientales) y en la aspiración a la diversificación de las actividades y las rentas de su población a la búsqueda de la pluriactividad. Parece claro que, en este aspecto, teoría y práctica se encuentran disociadas y que las áreas de montaña continúan siendo subsidiarias de una visión agrarista y, en consecuencia, subalternas de las políticas agrarias o, cuando menos, de las nuevas políticas de desarrollo rural ${ }^{20}$. Contradicciones palpables, en un momento en que se está produciendo una «desagrarización» acelerada, que parecen condenar a los espacios montañosos a conservar una base económica marginalizada y perpetuamente subsidiada.

Así viene ocurriendo desde que en 1975 se aplicó la primera Directiva Comunitaria sobre agricultura de montaña hasta las reformas de la PAC de 1992 y 2004 que, en aplicación de la Agenda 2000, integra la política agraria con el medio ambiente, especialmente con la aplicación de las medidas agroambientales y la indemnización compensatoria.

Las primeras acciones comunitarias específicas sobre las áreas de montaña se fundamentan en la Directiva (CEE) 268/75 sobre Agricultura de Montaña y de Ciertas Zonas Desfavorecidas que se considera como la medida inaugural de la determinación de las zonas de montaña en la Unión Europea, y que, a pesar de su alcance incuestionable en el ámbito de la ordenación del territorio, sigue aplicándose exclusivamente en el marco de la PAC.

La Directiva 268/75 establecía para estas zonas una normativa general cuya finalidad principal era compensar las rentas de los agricultores y ganaderos, en relación con las limitaciones que el medio natural montañoso impone para la práctica de dichas activida-

19 «pese a la existencia de un conjunto de medidas comunitarias que se destinan, o más bien incluyen a la montaña, no existe por el momento ninguna política estructurada respecto a los territorios de montaña, formada por medidas que se apliquen exclusivamente a esas zonas como consecuencia del reconocimiento de sus características y que responda a una estrategia deliberada global y coherente».

20 Puede ser conveniente recordar que el informe sobre «Medidas comunitarias en favor de las zonas de montaña» afirmaba en 2003 que las montañas tienen especificidades propias y que, aunque buena parte de las «zonas de montaña» también son «zonas rurales», ambos términos no son idénticos. 
des productivas, a través de una indemnización compensatoria de montaña (ICM) y otras inversiones colectivas.

Dicha directiva, actualizada por medio de varios reglamentos de «mejora de la eficacia de las estructuras agrarias», dejó a discreción de los Estados miembros la fijación de los parámetros para establecer la indemnización para los agricultores y ganaderos que viven en la montaña a partir de unos criterios básicos ${ }^{21}$. Esos criterios se han mantenido hasta hoy prácticamente incólumes en los sucesivos reglamentos que han regulado la distribución de los fondos en que se sustenta la financiación de la Política Agraria y de Desarrollo Rural Comunitaria.

Así sucede en el caso del REGLAMENTO del Consejo 1257/1999 sobre la ayuda al desarrollo rural a cargo del Fondo Europeo de Orientación y de Garantía Agrícola (FEOGA) que aúna las medidas que hasta ese momento se adoptaban en diferentes normativas (Directiva de zonas de montaña, reglamentos sobre mejora de la eficacia de las estructuras agrarias y sobre indemnizaciones compensatorias y otras medidas de acompañamiento ${ }^{22}$. Las áreas de montaña son consideradas en él como zonas con desventajas naturales que producen dificultades que hay que contrarrestar para «asegurar un uso continuado de las tierras agrarias y contribuir así al mantenimiento de una comunidad rural viable, conservar el campo y mantener y fomentar sistemas agrarios sostenibles con especial consideración a las exigencias medioambientales» (Art. 13).

En cuanto a la importancia de las ayudas medias, de escasa significación, nunca fueron determinantes en las rentas de los agricultores y ganaderos ${ }^{23}$. En el caso español, las ayudas superiores a $600 €$ por explotación sólo han rebasado el 7\% de las mismas en las Comunidades Autónomas de Canarias, Cantabria y Castilla-La Mancha; la mayor parte de las explotaciones han percibido entre 550 y $600 €$, salvo en Andalucía, Baleares, Extremadura, Murcia y Comunidad Valenciana, en las que mayoritariamente las ayudas son inferiores a $500 €$ por explotación (Ariza, 2005).

En la actualidad las políticas y las medidas específicas para las zonas de montaña se incluyen en el Eje 2 de la PAC, sobre gestión medioambiental de las tierras agrarias y forestales, y se apoyan financieramente en el Fondo Europeo Agrario de Desarrollo Rural (FEADER). De forma que, sin abandonar completamente la consideración agrarista, ésta parece estar siendo sustituida por una visión ambientalista como puede percibirse en el tratamiento que a las áreas de montaña otorga el nuevo Reglamento sobre el FEADER.

21 No parece conveniente insistir aquí en este aspecto puesto que la delimitación de las zonas de agricultura de montaña y la aplicación de la ICM ha sido uno de los temas más frecuente y abundantemente abordados en los análisis geográficos y de otras áreas de conocimiento interesadas en las actividades agrarias y los espacios rurales de montaña.

22 REGLAMENTO (CE) No 1257/1999 de 17 de mayo de 1999 sobre la ayuda al desarrollo rural a cargo del Fondo Europeo de Orientación y de Garantía Agrícola (FEOGA) y por el que se modifican y derogan determinados Reglamentos. L 160/80 ES Diario Oficial de las Comunidades Europeas 26.6.1999. Las zonas de montaña, consideradas como zonas desfavorecidas, son definidas como aquellas «que se caractericen por una limitación considerable de las posibilidades de utilizar la tierra y por un aumento apreciable de los costes necesarios para trabajarla a causa de: la existencia, debido a la altitud, de unas condiciones climáticas duras que acorten sustancialmente la temporada de cultivo, la presencia, a más baja altitud y en la mayor parte de la zona considerada, de pendientes que sean demasiado pronunciadas para el uso de maquinaria o que requieran la utilización de equipos especiales muy costosos, o una combinación de estos dos factores cuando, siendo menor la dificultad resultante de cada uno de ellos por separado, tal combinación dé lugar a una dificultad de grado equivalente» (Art. 18).

23 Las indemnizaciones compensatorias se fijan en un mínimo de $25 €$ y un máximo de $200 €$ por Ha de tierra agraria. Así mismo «podrá compensarse a los agricultores mediante pagos para compensar los costes y las pérdidas de renta que se produzcan en zonas con limitaciones medioambientales debido a la aplicación de limitaciones en la explotación agraria basadas en disposiciones comunitarias de protección medioambiental, siempre que dichos pagos sean necesarios para solucionar los problemas específicos emanados de dichas disposiciones» (Art. 16). 
Por otra parte, si bien se mantiene hasta el año 2010 el statu quo de las indemnizaciones compensatorias para las zonas desfavorecidas de la UE, y por tanto, para las zonas de montaña, su continuidad se justifica porque «Es preciso seguir prestando ayuda a los agricultores para que puedan hacer frente a las dificultades específicas en las zonas en cuestión, como consecuencia de la aplicación de la Directiva 79/409/CEE del Consejo, de 2 de abril de 1979, relativa a la conservación de las aves silvestres (1) y la Directiva 92/43/CEE del Consejo, de 21 de mayo de 1992, relativa a la conservación de los hábitat naturales y de la fauna y flora silvestres (2), a fin de contribuir a una gestión eficaz de las zonas Natura 2000» ${ }^{24}$.

En cualquier caso se trata de una continuidad limitada en el tiempo ${ }^{25}$ ya que se establece que «Las zonas de montaña y demás zonas con dificultades deben seleccionarse sobre la base de criterios objetivos comunes. Procede derogar por lo tanto, con efectos a partir de una fecha posterior, las Directivas y las Decisiones del Consejo por las que se adoptan las listas de zonas desfavorecidas o se modifican tales listas de acuerdo con el artículo 21, apartados 2 y 3, del Reglamento (CE) no 950/97 del Consejo, de 20 de mayo de 1997, relativo a la mejora de la eficacia de las estructuras agrarias (1).»

Precisamente éste ha sido uno de los motivos de preocupación de algunas organizaciones agrarias, que han considerado que la propuesta de la Comisión de redefinir la delimitación de zonas menos favorecidas, sin tener en cuenta criterios socioeconómicos actuales, podría redundar en una importante reducción de las áreas susceptibles de recibir apoyo y del nivel de apoyo de los propietarios de tierras de modo que, combinado con el desacoplamiento, como propone la reforma de la PAC, esta nueva definición de Zonas Desfavorecidas podría conducir a un completo abandono de la producción en muchas zonas rurales.

Asimismo se acusa al nuevo reglamento de desarrollo rural de dar prioridad a la estrategia de Lisboa sobre cualquier otra política de la UE, y de tener más presentes los objetivos de competitividad, crecimiento, empleo e innovación que los objetivos relacionados con el medio ambiente y la cohesión social. En la misma dirección parecen ir las declaraciones que hizo la Ministra de Agricultura en el sentido de manifestar su preocupación por la sostenibilidad económica, social y medioambiental de las zonas desfavorecidas y de solicitar la inclusión de criterios socioeconómicos en la delimitación de dichas zonas.

Si esas amenazas son reales, una de las claves para entenderlas hay que buscarla en el ausencia, otra vez, de un mayor enfoque territorial en el Reglamento puesto que sólo ese enfoque territorial puede permitir que el Desarrollo Rural se convierta en una verdadera política europea transversal, que garantice un acercamiento al objetivo de cohesión entre todos los territorios europeos, entre ellos las áreas de montaña.

Mas allá de la indemnización compensatoria de montaña, son muchas las medidas contempladas en la PAC que tienen interés para las áreas de montaña, aunque no se centren en ellas, y que constituyen instrumentos pertinentes para consolidar la actividad agraria, apoyar la protección ambiental y estimular el desarrollo en estas zonas: medidas agroambientales, forestales, de desarrollo rural, reglamentación de los productos de calidad controlada, de la agricultura biológica, de la modernización de los sectores agrarios, etc... No insistiré en ellas porque han sido profusamente abordadas en otras ocasiones y, además, porque no son asunto específico de este estudio.

24 REGLAMENTO (CE) 1698/2005 DEL CONSEJO de 20 de septiembre de 2005 relativo a la ayuda al desarrollo rural a través del Fondo Europeo Agrícola de Desarrollo Rural (FEADER). 21.10.2005 ES Diario Oficial de la Unión Europea L 277/1.

25 Considerando que «Determinadas disposiciones del Reglamento (CE) $n^{\circ}$ 1257/1999 relativas a la ayuda a las zonas desfavorecidas deben mantenerse en vigor durante un plazo determinado...» 
Existen, igualmente, otros tipos de acciones comunitarias que revisten una importancia especial para la regiones montañosas y en las que éstas se integran ampliamente, aunque las medidas contempladas no las mencionen expresamente. Son tres tipos de acciones en particular: la política de los Fondos Estructurales, las iniciativas INTERREG y LEADER que forman parte de esta política y las directivas sobre las aves, los hábitats y la Red Natura 2000.

Los Fondos Estructurales europeos siguen teniendo una gran relevancia para las áreas de montaña dado que se considera que en torno al $95 \%$ de estas zonas pueden acogerse al amparo de los actuales Objetivos 1 y 2 de la Política Regional, si bien hay que reconocer que esta admisibilidad no se debe a las características impuestas por los obstáculos naturales de la montaña, sino a su pertenencia a regiones menos desarrolladas o con graves problemas de reconversión económica. Esta situación podría reflejar una posible inadecuación entre los programas efectivamente financiados y la realidad de los problemas que se plantean.

Por lo que se refiere a la iniciativa INTERREG, cabe señalar que casi todas las regiones fronterizas montañosas de los estados miembros occidentales se acogen a alguna de las modalidades de este programa. INTERREG tiene ahora, por primera vez, un programa dedicado específicamente a las zonas de montaña, el del espacio alpino (Alpenraum), que cuenta con una cofinanciación de la Comisión Europea de 58 millones de euros ${ }^{26}$. INTERREG ha introducido además la gobernanza transnacional, una nueva forma de gestión de las políticas y de las acciones que sobrepasa las fronteras tradicionales.

En cuanto a la iniciativa LEADER, es de sobra conocido que buena parte de las comarcas de montaña de todos los países miembros se han implicado en las distintas fases de la iniciativa de manera que muchos Grupos de Acción Local se encuentran en áreas de montaña. Así, en Francia el 36 \% de los GAL-LEADER+ se sitúan en zonas de montaña; en España, en general, tanto LEADER I como LEADER II y LEADER+ se han desarrollado en comarcas rurales de los macizos montañosos, destacando la concentración de Grupos de Acción Local en el Sistema Ibérico, los Pirineos, las sierras de los Sistemas Bético y Penibético, y de la Montaña Cantábrica.

Los nuevos Estados miembros y los países candidatos disponen de programas similares, PHARE y SAPARD, adecuados a las zonas de montaña. Así, Rumania tiene un programa PHARE centrado específicamente en la «Agricultura en las zonas de montaña» que cuenta con la ayuda de Francia y Alemania.

La Red Natura 2000 está lógicamente muy vinculada a los territorios de montaña como consecuencia de la extraordinaria calidad y diversidad del patrimonio natural montañés. Es necesario subrayar, por otra parte, que junto al ámbito biogeográfico alpino, numerosas propuestas de zonas de montaña Natura 2000 también están incluidas en los ámbitos biogeovos:

26 Espacio alpino/Alpes orientales. Participan Alemania, Italia y Austria (más Suiza y Eslovenia). Objeti-

- continuación del desarrollo de visiones y estrategias comunes de desarrollo territorial a partir del documento «Principios de una política europea de desarrollo territorial» (Leipzig), así como de otros documentos importantes (Venecia 1996);

- fomento de redes transnacionales, transfronterizas y transeuropeas entre las autoridades regionales y locales de los Alpes, en particular, en el ámbito de la ordenación del territorio;

- mejora y desarrollo de actividades socioeconómicas sostenibles, así como de redes de transporte locales respetuosas con el medio ambiente, especialmente en las regiones ambientalmente sensibles. Desarrollo de nuevas formas de sensibilización de la población local para incitarla a comprometerse en mayor medida con la protección y cuidado de las zonas frágiles y amenazadas;

- puesta a prueba de una serie de líneas de actuación innovadoras en una región que presenta un fuerte potencial de conflicto entre la prosperidad económica y la protección del medio ambiente.

(E.T.E., pp. 85). 
gráficos «continental» (como, por ejemplo, el Macizo Central en Francia), «mediterráneo» (como el Pindo en Grecia o los Apeninos en Italia), «marroquí» (Gibraltar), o «Atlántico» (la Cordillera Cantábrica en España).

Con las directivas «Hábitats» y «Aves», la Red Natura 2000 cubre ampliamente las montañas europeas, aunque, según afirman algunos expertos, «sin preocuparse suficientemente de sus habitantes y de las poblaciones de montaña» (Maitia, 2006), de manera que parece ser un ejemplo claro de una posible contradicción entre la gestión sostenible del territorio y el desarrollo sostenible del territorio y sus habitantes.

A una escala inferior a la comunitaria hay que resaltar la existencia de algunas políticas de montaña de carácter transnacional que se concretan en la Convención Alpina y la Convención de los Cárpatos.

La Convención Alpina comenzó a gestarse en 1989 con el objetivo a largo plazo de promover el desarrollo sostenible del territorio alpino, salvaguardando los ecosistemas naturales y protegiendo los intereses económicos de las poblaciones residentes mediante el establecimiento de principios en los que se debería inspirar la cooperación transfronteriza entre los países del Arco Alpino ${ }^{27}$. Para alcanzar esos objetivos los países contratantes han debido adoptar las medidas oportunas en varios aspectos concretos, especificados en una serie de protocolos, sobre ordenación y desarrollo sostenible del territorio, protección de la naturaleza y mantenimiento de los paisajes, agricultura de montaña, bosques de montaña, protección de suelos, turismo y ocio, energía, transportes, calidad del aire, régimen de las aguas, población y cultura y residuos.

El proceso de constitución ha sido largo y aún queda mucho para su implementación completa. Se puede considerar, no obstante, que se ha culminado una primera fase en 1995 con la firma de la mayoría de los protocolos, aunque todavía quedan algunos por elaborar. El resultado de esta primera etapa ha sido el reconocimiento de los Alpes como un espacio unitario desde una perspectiva global, un espacio en el que la naturaleza, la economía y la cultura se imbrican y son interdependientes, en el que las diferentes peculiaridades se integran en una identidad que exige una protección supranacional.

La Convención de los Cárpatos es también un acuerdo marco de cooperación transnacional firmado en 2003 entre Chequia, Hungría, Polonia, Rumania, Serbia, Montenegro, Eslovaquia y Ucrania. Así mismo, sus objetivos, se concretan en protocolos temáticos que contemplan simultáneamente aspectos medioambientales, sociales y económicos.

Con unos objetivos menos ambiciosos se constituyó en 1983 la Comunidad de Trabajo de los Pirineos; se trata de un organismo de cooperación fronteriza que engloba a las a las Comunidades Autónomas españolas de Aragón, Cataluña, Navarra y País Vasco, las regiones francesas de Aquitania, Midi-Pyrénées y Languedoc-Roussillon y el Principado de Andorra. Como se recoge en el acuerdo fundacional y, posteriormente, en el Reglamento de organización y funcionamiento de la propia Comunidad de Trabajo, aprobado en 1989, entre los objetivos que persigue la Comunidad de Trabajo de los Pirineos destaca el de reunirse regularmente para intercambio de informaciones y discusión de todas aquellas cuestiones técnicas que aporten soluciones coordinadas para el interés común de sus miembros, especialmente en los ámbitos de: transportes y vías de comunicación, movimiento portuario y pesca, problemas energéticos, agricultura, economía forestal y de montaña, economía hidráulica, promoción del turismo y del termalismo, protección de los recursos y del me-

27 Se ha partido de la consideración de que una explotación creciente por parte del hombre puede constituir una amenaza cada vez mayor para el territorio alpino y sus funciones ecológicas y que únicamente la armonización de los intereses económicos con las exigencias ecológicas puede evitar perjuicios cuya reparación, si fuera posible, implicaría un derroche enorme de recursos y de tiempo. 
dio naturales, protección de parajes, protección del mar, lagos y de los cursos del agua, ordenación del territorio y urbanismo, desarrollo regional y rural, problemas de formación para el desarrollo, protección del entorno social y Patrimonio cultural.

Otras comunidades de trabajo son las de los Alpes occidentales constituida en 1982 (COTRAO), los Alpes centrales (ARGE-ALP, 1972), los Alpes orientales (ALPE-ADRIA, 1978) y el Jura (Francia y Suiza, 1985). Algunas de estas iniciativas se han apoyado recientemente en programas INTERREG.

Descendiendo de la escala comunitaria a la estatal, se observa que casi todos los Estados de la UE poseen alguna forma de política que afecta implícita o explícitamente a las áreas de montaña. Sólo carecen de ellas los países que no tienen, o apenas tienen, áreas de montaña propiamente dicha (Dinamarca, Países Bajos, Países Bálticos), o, en el extremo opuesto, los muy montañosos porque la extensión generalizada de las áreas de montaña hace innecesaria una política propia (Grecia, Eslovenia, Noruega).

Por otro lado están los países que sólo aplican a sus áreas de montaña políticas de carácter sectorial, orientadas por lo general a la agricultura, el medio ambiente y el turismo, como es el caso de la mayoría de los de la última ampliación y los países con predominio de las montañas medias, principalmente Irlanda y Portugal.

Frente a ellos, otro conjunto de países ha esbozado políticas de montaña orientadas a obtener un desarrollo multisectorial que han sido puestas en práctica a nivel regional (Alemania, España y Austria). Si bien la base de sus políticas suele ser la actividad agraria, al encontrarse ésta en retroceso han ido ampliando paulatinamente el campo de actuación a otros sectores, sobre todo el turismo, el medioambiente, las dotaciones infraestructurales y los equipamientos.

Por último hay que destacar un limitado número de países que disponen de una legislación específica para sus áreas de montaña, en algunos casos con el ambicioso objetivo de alcanzar un desarrollo global hasta el punto de que se las puede calificar como políticas integradas. En esa situación se encuentran Francia, Italia y Suiza. También Noruega posee una política de montaña integrada pero, por la generalización de su territorio montañoso, no se dirige específicamente a las zonas de montaña. Bulgaria y Rumania han elaborado recientemente una política de montaña integrada siguiendo el modelo francés e italiano.

Hay que advertir previamente, no obstante, que el concepto de política de montaña integrada no es unívoco. Algunos países la entienden como una política multisectorial, en tanto que para otros se trata de una amalgama de política regional y agraria o de políticas sectoriales y territoriales.

La primera legislación de estas características fue la Ley suiza sobre Inversiones en las regiones de Montaña (LIM), aprobada en 1974 y revisada en 1997, que no se considera de forma unánime como una política integrada.

En Italia, la Constitución de 1948 mencionaba las montañas como zonas caracterizadas por necesidades específicas; en 1971 se aprobó la ley que definía las comunidades de montaña como grupos de municipios, o partes de municipios, que funcionan como instrumento específico para llevar a cabo la política de montaña que, finalmente, quedó definida en 1994 por una Ley sobre la Montaña.

En este sentido Francia constituye el modelo de referencia. La primera delimitación de montaña en Francia se hizo en 1961. En 1973 se acuñó el concepto de macizo, que incluye las áreas de montaña propiamente dichas y las contiguas que conforman con ellas una entidad geográfica, económica y social. Las áreas de montaña, definidas en función de sus desventajas económicas y sociales, además de las naturales consideradas en un segundo plano, fueron reconocidas legalmente por la Ley de Montaña promulgada en 1985 y, de acuerdo con dicha Ley, fueron delimitados los macizos en 1995. Esta legislación sirve de 
soporte a diversas instituciones como el Consejo Nacional de Montaña y los comités de Macizo, que gestionan las medidas destinadas, primero, a mantener la agricultura de montaña relativamente al margen de su nivel productivo y, después, a apoyar la multifuncionalidad de los espacios rurales y la pluriactividad de sus habitantes.

Francia también elaboró precozmente políticas sectoriales orientadas al desarrollo turístico de la montaña (Plan de nieve de 1970) y su protección medioambiental (Parques Nacionales).

En ocasiones ha sido considerada como política integral de montaña, erróneamente a mi juicio, la legislación aplicada específicamente a la agricultura de montaña en algunos países como es el caso de Austria y España.

La ley austriaca de 1972 es, en realidad, un programa especial para los agricultores de montaña que intenta compensarles en proporción a las dificultades que les imponen la topografía de las montañas, el clima y la distancia de los mercados. Bien es verdad que se considera que esta política ha permitido asegurar que todos los agricultores obtengan unas rentas adecuadas y que ha sido decisiva para conservar la pequeña agricultura en las zonas de montaña.

La Ley 25/1982 de 30 de junio de Agricultura de Montaña (LAM) ha sido interpretada como la primera norma jurídica que aborda en España la problemática de las Zonas de Montaña desde un enfoque integrado. De hecho, a partir de ella se manejan nociones como las de la pluriactividad, desarrollo sostenible y multisectorial e, incluso, se perfila la participación de la población montañesa en los programas de desarrollo.

La LAM, por otra parte, establece como objetivo fundamental el desarrollo de las Zonas de Montaña a partir de la conservación, utilización, explotación y defensa del medio físico, la mejora del hábitat rural y el incremento de las rentas de las familias que viven y trabajan en las Zonas de Montaña.

En el mismo sentido cabe considerar el diseño de los Programas de Ordenación y Promoción de Recursos Agrarios de Montaña (PROPROM, R.D. 2164/84) como instrumentos básicos de desarrollo de las Zonas de Agricultura de Montaña (ZAM).

No obstante, la realidad no fue mucho más lejos de la delimitación que, de acuerdo con las competencias transferidas, cada Comunidad Autónoma hizo de las Zonas de Agricultura de Montaña (ZAM) con el objeto de establecer los correspondientes PROPROM y, más tarde, para gestionar las Indemnizaciones Compensatorias de Montaña. En total, se calificaron como municipios de montaña en toda España 3.076, el 38,5\% del total de los municipios españoles, que ocupan una superficie de $208.000 \mathrm{~km}^{2}$, el $41 \%$ de la superficie total del país.

El número de PROPOM desarrollados fue escaso y su operatividad más que discutible. No obstante, es generalmente aceptado que la experiencia adquirida en el desarrollo de los PROPROM sirvió de base a un buen número de Grupos de Acción Local de la iniciativa LEADER (Serranía de Cuenca, Montañas y Valles Alaveses, Montaña Palentina, Alto Palancia-Alto Mijares, Pinares-El Valle en Soria y Burgos, etc.).

A nivel regional, en el caso español, la propuesta que más se aproxima a una política de montaña integrada es la contenida en la Ley de Alta Montaña de Cataluña, promulgada en 1983 y desarrollada a partir de 1989 a través de la formulación de Planes Comarcales de Montaña ${ }^{28}$. También en Cataluña se ha aprobado en 2002 una nueva ley con el objeti-

28 «1.Son comarcas de montaña, a los efectos de la presente Ley, los territorios homogéneos con unidad territorial, económica y social que estén o puedan estar organizados como áreas socio-económicas funcionales y que, al mismo tiempo, se caracterizan por:

a. Tener una altitud, una pendiente y un clima claramente limitadores de las actividades económicas. 
vo de crear el Instituto para el Desarrollo y la Promoción del Alto Pirineo y Arán ${ }^{29}$ (Alta Ribagorca, Alt Urgell, Cerdanya, Pallars Jussá y Pallars Sobirá y Aran) considerando que «constituyen una unidad territorial con una especificidad propia» y que deben «comportar un tratamiento diferenciado» para conseguir su «desarrollo integral».

Algunos autores consideran relativamente equivalente a una política de montaña el programa de Agricultura de Montaña desarrollado en el País Vasco desde 1986 a través de las Asociaciones de Agricultura de Montaña, constituidas a partir de la entrada en vigor del DECRETO 394/1985, sobre el Régimen específico de la Agricultura de Montaña en la Comunidad Autónoma del País Vasco. Si bien se reconoce la primacía de la visión agrarista, se afirma que los objetivos, «coinciden con los habituales en los programas de desarrollo rural impulsados por la CE» (Alberdi Collantes, 2002).

En Aragón se ha presentado, mediante una iniciativa legislativa popular, un proyecto de Ley para la Protección de la Alta Montaña de Aragón entre cuyos objetivos está la revitalización del medio rural de montaña mediante la elaboración de un Plan de Desarrollo Rural Sostenible de las Areas de Montaña, o instrumento equivalente, «que preste especial atención a aquellas zonas en las que se produzcan situaciones de envejecimiento demográfico y pérdida de población residente, infrautilización de recursos naturales, culturales o patrimoniales, declive económico y abandono de explotaciones familiares». Pese a las movilizaciones realizadas hasta ahora, las instituciones públicas han prestado escasa atención a la propuesta.

Por el contrario, muy recientemente, en Asturias se ha iniciado el proceso de elaboración de un programa de desarrollo integrado para sus áreas de montaña a partir de la firma de un Convenio de colaboración entre el Principado de Asturias, a través de la Consejería de Medio Rural y Pesca, y el Ministerio de Agricultura, Pesca y Alimentación para la elaboración de «una estrategia a favor del desarrollo rural sostenible de las zonas de montaña (I+D local, medio ambiente y cultura rural) $\gg^{30}$. Tomando como referencia el Principado de Asturias, considerado como la región más montañosa de España, el objetivo final supera el marco regional ya que consiste en «la redacción de un documento que sirva de referencia para la elaboración de una estrategia nacional para las zonas de montaña»(Cláusula $4^{\mathrm{a}}$ ).

b. Disponer de recursos que son escasos en el conjunto del territorio de Cataluña, especialmente agua, nieve, pastos, bosques y espacios naturales.

c. Tener una baja densidad de población en relación con el valor medio de Cataluña.

2. Se consideran comarcas de montaña, a los efectos de la presente Ley, las siguientes comarcas: l'Alt Urgell, la Cerdanya, el Pallars Jussà, el Pallars Sobirà, el Ripolles, la Vall d'Arán, el Berguedà, el Solsonès i la Garrotxa, en la integridad de su territorio». (http://juridicas.com/base datos/CCAA/ca-12-1983.html).

29 LEY 28/2002, de 30 de diciembre, de creación del Instituto para el Desarrollo y la Promoción del Alto Pirineo y Arán. http://www.todalaley.com/mostrarLey1000pltn.htm

30 BOE, n 125, Viernes, 26 mayo 2006, 19915 y BOPA, $n^{\circ}$ 112, Miércoles, 17 de mayo de 2006. En el considerando decimotercero se afirma que «se hace necesario formular una reflexión estratégica general a favor de las zonas de montaña, y por extensión los territorios rurales desfavorecidos, que sirva de marco para la elaboración integrada de políticas sectoriales y para la puesta en marcha de estrategias regionales y locales de desarrollo rural que contemplen de forma simultánea el desarrollo integrado y la conservación de los agroecosistemas». La tercera claúsula establece que «Los objetivos de la estrategia para las zonas de montaña se centran en los siguientes campos de trabajo:

1. Paisaje, biodiversidad y agricultura. Uso sostenible de los recursos naturales y modernización de los sistemas tradicionales de manejo del medio: Ganadería, agricultura de montaña y silvicultura.

2. Diversificación socioeconómica.

3. Aprovechamiento de energías renovables desde la perspectiva del desarrollo local.

4. Despoblamiento rural y nuevos pobladores.

5. Conservación y dinamización del patrimonio natural y cultural.

6. Nuevas formas para la gestión integrada de los territorios rurales». 
En la mayor parte de los casos, tanto a escala comunitaria, como estatal y regional, la mayoría de las llamadas políticas de montaña puestas en práctica son medidas sectoriales con adaptaciones específicas. Las acciones de carácter estrictamente sectorial sobre las áreas de montaña europeas han sido bastante más numerosas, tanto a escala comunitaria, como estatal, regional y local.

Desde una perspectiva agraria, además de las medidas vinculadas a la PAC, se han desarrollado políticas orientadas a mantener el uso del suelo más que a producir. Sirvan de ejemplo los programas de protección de paisajes culturales de Baviera en Alemania, Austria, Suiza, Irlanda, o las medidas orientadas a la conservación, mejora y gestión de pastos de Francia, España (sobre todo en Asturias y las comarcas pirenaicas), Alemania, Italia, Austria; las dirigidas a la protección de masas forestales y de las actividades productivas basadas en ellas (selvicultura). En general parece que se trata de políticas ambiciosas, pero insuficientes y generalmente más vinculadas a objetivos medioambientales que económicos.

Las actividades industriales, mineras y manufactureras, bien arraigadas tradicionalmente en algunas zonas de montaña, también han sido objeto de intervención, bien para preservarlas, bien para renovarlas o, incluso, para implantarlas ex novo. Aunque, en general, han sido muy pocas las políticas que se han puesto en práctica para sostener específicamente tales actividades, pueden citarse algunos ejemplos como el programa piloto «Regionen aktiv» en Alemania y algunos otros en la República Checa o en Bulgaria.

Desde el enfoque sectorial son las actividades relacionadas con el turismo, sin ninguna duda, las que han sido primadas con un mayor número de acciones, si bien, como denuncia el informe elaborado por la Comisión, «las políticas aplicadas por las autoridades públicas a fin de desarrollar el turismo son muy débiles y pocas iniciativas se han orientado específicamente al turismo de montaña» (Nordregio, 2004,162). El apoyo al turismo se ha desarrollado por la vía de las iniciativas locales en cooperación con las asociaciones turísticas y ni siquiera en Suiza, el país más montañoso, existe una política federal centrada en el turismo de montaña. A falta de iniciativas específicas, es obligado mencionar la importancia de los proyectos que fomentan el desarrollo turístico en el marco del LEADER.

Afortunadamente, las políticas orientadas a mejorar las infraestructuras de las áreas de montaña, en particular las de transporte, empiezan a tener cierta importancia. En este aspecto las políticas aplicadas en Suiza son una referencia inexcusable; pero también en otros Estados, como Suecia y Noruega, se han desarrollado políticas de infraestructuras que favorecen las montañas y su periferia.

A través de intervenciones recientes, el nivel de accesibilidad por carretera de las áreas de montaña europeas ha sido sensiblemente mejorado en los últimos años, particularmente en las zonas de montaña más desfavorecidas donde los proyectos son seleccionables por el Objetivo 1.

En otras zonas de montaña el problema no es tanto la accesibilidad cuanto el incremento excesivo del tráfico de tránsito (Alpes y Pirineos, p.ej.); se trata de prestar especial atención a la sustentabilidad, la limitación de tránsitos en estas zonas y el reequilibrio de los medios de transporte a favor del ferrocarril. Tales aspectos han sido también abordados mediante intervenciones públicas orientadas a transferir la carga del transporte por carretera al transporte ferroviario, como hace el proyecto «Rail 2000» para el trayecto Lyon-Turin en colaboración con la Comisión Europea y a través de convenios bilaterales entre Alemania, Francia e Italia.

Una de las deficiencias infraestructurales de las zonas de montaña, que resulta especialmente grave en el presente y, sobre todo, de cara al futuro, es el acceso a las nuevas tecnologías de la información y de la comunicación (TIC), ya que son un medio de compensar la débil accesibilidad física de las áreas de montaña. Para corregirlo están comenzando a aplicarse políticas públicas en un buen número de comarcas montañosas. 
También empiezan a ser objeto de atención preferente las condiciones de vida en las áreas de montaña, en particular por lo que se refiere a la vivienda dado que, en general, representa un problema clave, sobre todo por los déficits de equipamientos domésticos y por la antigüedad de las construcciones. A él hay que añadir los problemas que derivan de la proliferación de residencias secundarias de nueva construcción.

Algunos ejemplos de medidas adoptadas en este sentido son la supresión de impuestos locales para la construcción en áreas de montaña (Portugal), la concesión de subvenciones para la rehabilitación de edificios en los pueblos de montaña (Francia, España), la aplicación de programas a favor del alojamiento en pueblos pequeños (PROSIURB en Portugal).

Algo similar sucede con los servicios públicos, uno de los aspectos que acrecientan la desigualdad de oportunidades de los habitantes de las áreas de montaña. La conservación y la mejora de los servicios públicos en las zonas de montaña es un requisito imprescindible no sólo en términos de igualdad, sino también de desarrollo del atractivo para nuevos residentes y turistas. Por eso se están aplicando medidas orientadas a la concentración de instalaciones y servicios en núcleos centrales, estableciendo sistemas de transporte a la demanda, por medio de minibús o taxis, y de enseñanza a distancia, estimulando mediante la concesión de subvenciones el establecimiento de empresas comerciales itinerantes y de servicios móviles, desarrollando proyectos «E-mountain» (Italia) para la provisión de servicios administrativos públicos a los ciudadanos y a las empresas, etc. Citar ejemplos concretos resultaría demasiado prolijo.

La puesta en práctica de políticas que se enfrenten a la preservación del medio ambiente y de los paisajes montañeses es también una prioridad de las políticas públicas a través de la ordenación del territorio, aunque prácticamente en ningún país existe un instrumento de reglamentación y de orientación de la ordenación específica para las zonas de montaña.

En las políticas generales de medio ambiente destaca la Directiva sobre la evaluación del impacto medioambiental y el Programa LIFE que, en el marco de Natura 2000, permite financiar proyectos de ordenación o rehabilitación de espacios naturales. No obstante, se ha recurrido también a algunos instrumentos específicos para las zonas de montaña como el sistema de Unidades Turísticas Nuevas (UTN) de Francia, el Plan de Utilización del Suelo en Áreas Protegidas (POAP) de Portugal, o el Plan de los Alpes en Baviera (Alemania).

En cuanto a la protección del patrimonio natural, cada país posee su propio sistema adaptado a las diferentes condiciones nacionales. A escala de la UE, el programa Natura 2000, desarrollando las directrices «especies» y «hábitats», es el instrumento principal de protección aunque su aplicación acusa importantes retrasos en numerosos países.

\section{La ineludible exigencia de una política integrada específica para las áreas de mon- taña}

A la vista de lo expuesto hasta aquí, no parece exagerado afirmar que las intervenciones públicas, comunitarias y estatales, orientadas a estimular el desarrollo en las áreas de montaña han sido, al menos hasta el momento, un cúmulo de medidas a veces no demasiado congruentes entre sí. De hecho, en los programas de desarrollo rural contenidos en los Marcos Comunitarios de Apoyo, las zonas de montaña no han sido contempladas de forma específica, sino que sus requerimientos particulares han sido únicamente objeto de medidas de acompañamiento de la PAC y, a lo sumo, del incremento de porcentajes de ayuda en determinadas acciones sectoriales.

Tales medidas constituyen un marco legal a todas luces insuficiente. La mejor prueba de que estas actuaciones dispersas no están siendo eficaces se encuentra en el hecho de que las 
áreas de montaña han visto agravados sus problemas en las últimas décadas: continúa la atonía de sus tejidos socioeconómicos, la población sigue disminuyendo y masculinizándose, bastantes tierras de cultivo, incluso algunas entidades, son abandonadas, etc.

Queda claro que las áreas de montaña requieren algo más que acciones sectoriales que, aunque a veces pueden llegar a generar crecimiento económico, producen también en muchas ocasiones graves desequilibrios y una excesiva dependencia del exterior (Laguna, 2005, 230). Por eso no puede extrañar que la reclamación de una política integrada y específica para las áreas de montaña, orientada a atajar los problemas de despoblación y empobrecimiento, comience a ser un clamor generalizado.

En la ya citada conferencia «Las Políticas Comunitarias y la Montaña» de octubre de 2002 se afirmó tajantemente que «Se precisa una política de montaña que integre todas las necesidades de las distintas regiones y todas las tendencias: economía y protección del medio ambiente, turismo y transporte, etc. Se necesita reforzar la reproducción de estos hábitats y proteger no sólo la naturaleza sino también las personas que viven en este medio, a través de la protección del patrimonio cultural y social. La promoción del espíritu empresarial y de la competitividad son fundamentales, ya que existe en la actualidad una tendencia alarmante hacia la polarización de la actividad económica en la UE que supone una amenaza especial para las zonas de montaña, al desplazarse las inversiones hacia las zonas de crecimiento» (el subrayado es mío).

Por las mismas fechas, la Asociación Europea de Autoridades Políticas de Regiones de Montaña insiste en el mismos aspectos, haciendo un llamamiento «a todos los países europeos para que elaboren y pongan en práctica una política nacional o políticas regionales de montaña, o para que las profundicen cuando ya existen legislaciones nacionales o regionales; invita a los órganos de la Unión Europea a elaborar y poner en práctica instrumentos comunitarios específicos para las regiones de montaña a partir de 2006»" (los subrayados son míos).

En la Estrategia Territorial Europea se insiste en que «las montañas son unidades territoriales que gozan de una identidad específica... son buenos ejemplos para ilustrar la necesidad de un proceso coordinado destinado a solucionar problemas comunes, a reforzar objetivos comunes y a fomentar una mayor cohesión territorial»(ETE, 1999, pp. 60-61).

¿Qué razones explican, por tanto, que hasta ahora se haya avanzado tampoco en esa dirección?

El propio Comité Económico y Social Europeo aporta una parte elocuente de la respuesta al afirmar que la Unión Europea no ha reconocido aún la especificidad de las zonas de montaña, al menos desde una perspectiva normativa ${ }^{31}$. Eso explica que, según el mismo documento, «pese a la existencia de un conjunto de medidas comunitarias que se destinan, o más bien, incluyen a la montaña, ya sea en la práctica o potencialmente, no existe por el momento ninguna política europea estructurada respecto a los territorios de montaña. formada por medidas que se apliquen exclusivamente a estas zonas como consecuencia del reconocimiento de sus características específicas, y que responda a una estrategia deliberada, global y coherente» (el subrayado es mío). De ahí la importancia decisiva que se otorga, vanamente como luego se pudo comprobar, a la reflexión territorial que iniciaba

31 «Los territorios de montaña han ocupado un lugar variable en las políticas comunitarias y han sido objeto de mayor o menor atención según las épocas. De hecho, en el estado actual del Derecho comunitario y a falta de que se reconozca su especificidad, las zonas de montaña no constituyen un concepto verdaderamente “comunitarizado"» «El futuro de las zonas de montaña en la Unión Europea» (2003/C 61/19), Dictamen aprobado por el Pleno del Comité Económico y Social Europeo en la sesión del 18 de septiembre de 2002. 
por esas fechas la Comisión, que debía plasmarse en el Seminario europeo que se celebró en Bruselas en octubre de 2002 sobre la problemática de los territorios de montaña y que debía constituir «un acontecimiento esencial para el futuro de estos territorios» ${ }^{32}$.

Unos años más tarde, François Maïtia, miembro de la AEM, afirma que «La montaña es uno de los territorios peor conocidos por la Comisión Europea» puesto que «La dimensión territorial es relativamente nueva en el debate sobre las políticas europeas.» (Maitïa, 2006). El hecho de que, a diferencia de las islas, las zonas de montaña no hayan sido reconocidas ni mencionadas explícitamente en los tratados comunitarios, avala estas afirmaciones. Por ello, es imprescindible, en primer lugar, que se produzca ese reconocimiento ${ }^{33}$.

No obstante, también es cierto que la montaña se ha integrado recientemente en el debate sobre la cohesión al tiempo que quedaba incluida la dimensión territorial. Así lo pone de relieve la mención explícita de las zonas de montaña en el artículo III-220 del Tratado Constitucional que trata de la Cohesión económica, social y territorial ${ }^{34}$. Si bien aparecen incluidas en último lugar entre el resto de las áreas desfavorecidas, se considera que éste es un paso importante para el reconocimiento de las regiones de montaña que podría servir de base para el desarrollo de una política europea de montaña.

El primer requisito indispensable es, por tanto, el reconocimiento legal de las zonas de montaña en los documentos comunitarios que otorguen competencias específicas a las colectividades territoriales de montaña, o ventajas particulares a los actores económicos y/o a las poblaciones de las áreas de montaña (Nordregio, 2004).

Por otra parte, y en relación con lo anterior, existe un acuerdo casi universal en que otro paso previo para cualquier futura política de montaña europea es «la obtención de una definición que sea válida y aplicable a todo el territorio comunitario» (Sanz Tolosana, 2005: 177) que supere la disparidad actual de definiciones construidas básicamente con miras a la política agraria.

Los criterios usados hasta ahora deben ampliarse y completarse utilizando indicadores sociales y ambientales. A ello se comprometía el Comisario de Política Regional, Michel Barnier, en su breve balance sobre la política regional y la montaña de octubre de $2002^{35}$. Según el informe de Nordregio para la Comisión Europea, que parece ser el estudio anunciado, tal compromiso no ha sido cumplido, ni se han establecido nuevos criterios mientras que los nuevos estados miembros siguen aplicando los mismos o similares, básicamente agrarios, que sirvieron para delimitar las zonas de montaña en los años setenta y ochenta.

32 Ibidem.

33 Dictamen del Comité Económico y Social Europeo sobre el tema «Cómo garantizar una mejor integración de las regiones con desventajas naturales y estructurales permanentes», Bruselas, 10 de febrero de 2005. «Ya en su Dictamen sobre «El futuro de las zonas de montaña en la Unión Europeal» el CESE consideraba indispensable establecer una visión común mediante el reconocimiento de la especificidad estos territorios en los Tratados, tal como se hace en los citados artículos 158 y 299 del Tratado de Ámsterdam»

34 «A fin de promover un desarrollo armonioso del conjunto de la Unión, ésta desarrollará y proseguirá su acción encaminada a reforzar su cohesión económica, social y territorial.

En particular, la Unión intentará reducir las diferencias entre los niveles de desarrollo de las distintas regiones y el retraso de las regiones menos favorecidas.

Entre las regiones afectadas se prestará especial atención a las zonas rurales, a las zonas afectadas por una transición industrial y a las regiones que padecen desventajas naturales o demográficas graves y permanentes como, por ejemplo, las regiones septentrionales con una escasa densidad de población y las regiones insulares, transfronterizas y de montaña».

35 «Se está realizando, además, un estudio sobre las zonas de montaña, con el objetivo de definir los criterios de determinación de estas zonas y redefinir cuáles son en la UE; se recogerán una serie de indicadores sobre la geografía, la demografía, la situación socio-económica, la agricultura, infraestructuras, medio ambiente y riesgos naturales. Los primeros resultados estarán listos a principios de 2003 y los definitivos, a mediados de 2003. 
Por otra parte, parece unánime la opinión de que es preciso ampliar el concepto de zona de montaña de forma que ésta se entienda como un territorio continuo que incluya tanto la zona de montaña propiamente dicha como las áreas contiguas que están vinculadas funcional, social y económicamente a ella, frente a la situación actual de consideración de zonas de montaña aisladas. La inclusión se justifica por la influencia decisiva y recíproca de las áreas de montaña y sus colindantes en las actividades económicas, sociales y medioambientales.

Una segunda condición es, en consecuencia, una delimitación equilibrada de las áreas de montaña que integre los espacios naturales, los espacios rurales de alta densidad y las entidades de población cuyo funcionamiento esté directamente vinculado a la zona de montaña correspondiente. Este hecho es inseparable del reconocimiento del carácter transregional, e incluso transnacional, de las áreas de montaña.

A partir de estos requerimientos previos, se considera imprescindible definir un marco jurídico regulador del desarrollo integral de las zonas de montaña. Los objetivos concretos deben centrarse en la dinamización y diversificación de las actividades económicas montañesas, tanto las agrarias como las vinculadas a otros sectores productivos, tendentes a lograr la autonomía económica de la población montañesa en igualdad de condiciones con los habitantes de otras áreas; el mantenimiento de la población y del uso y la organización antrópicos del espacio montañés; la preservación de su diversidad natural y cultural mediante una interacción positiva entre las actividades humanas y el medio; el conocimiento real y realista de las áreas de montaña, de sus ventajas e inconvenientes, etc.... en el diseño, en definitiva, de una verdadera estrategia de desarrollo sostenible y equitativo, es decir, basado en la gestión equilibrada de los territorios y los recursos y respetuoso con los intereses de la población local.

El paso siguiente debería ser la plasmación de esa estrategia en la implementación de medidas de montaña, normativas y financieras, comunitarias y estatales, que aborden la gestión y la protección de los recursos naturales y de los paisajes, los conflictos económicos de estos territorios y los problemas sociales de sus habitantes, que deben ser los destinatarios principales, aunque no únicos, de las políticas integradas de montaña.

Tales políticas deben orientarse tanto a reducir los obstáculos superables como a compensar las desventajas naturales insalvables que sufren las zonas de montaña. Por ello se recomienda centrarlas en tres ejes:

- Compensación de los obstáculos insalvables a través de la aplicación de estrategias «reactivas» orientadas a paliar las desventajas naturales y las dificultades estructurales. Tal estrategia tiene como objetivo, en primer lugar, a mantener o renovar las actividades tradicionales promoviendo sistemas de compensación financiera para todas las actividades, agrarias y extraagrarias, afectadas negativamente, no aplicando los compromisos de reducción de la producción agraria previstos para las áreas sin desventajas, etc.

- Reducción activa de los obstáculos superables mediante estrategias «proactivas» que eliminen los obstáculos superables y permitan construir una nueva economía de montaña en torno a la estimulación de las actividades turísticas y otras del sector servicios, de las producciones agrarias de alta calidad e, incluso, de industrias de alta tecnología. La mejora de la accesibilidad y, en general, la de las dotaciones en infraestructuras y equipamientos es un requisito inexcusable para este tipo de estrategia.

- Estrategias de sustentabilidad a partir de la preservación de los recursos naturales y culturales que implican la protección y gestión del patrimonio territorial conside- 
rado como la mayor baza de que disponen las áreas de montaña. La valorización de sus señas de identidad es la que les permitirá redefinir su papel en un contexto socioeconómico y territorial que evoluciona a gran velocidad y que es predominantemente urbano.

Finalmente, para llevar a cabo con eficacia las políticas diseñadas se recomienda la existencia de un marco político sólido que apoye la especificidad de las zonas de montaña, defienda su importancia ambiental, económica y social, promueva la cooperación a todos los niveles y escalas y coordine las acciones sectoriales y territoriales a través de instituciones específicas encargadas de la aplicación y el seguimiento de las políticas públicas.

\section{BIBLIOGRAFÍA}

ABREU y PIDAL, J.M. de (2002): Análisis de las áreas de montaña españolas: análisis y recopilación. Fundación Conde del Valle de Salazar, Escuela Técnica Superior de Ingenieros de Montes, Madrid.

ALBERDI COLLANTES, J.C. (2002): «Una década de desarrollo rural en el País Vasco: Las Asociaciones de Agricultura de Montaña en Guipúzcoa» en Sancho el Sabio: Revista de cultura e investigación vasca, $\mathrm{n}^{\circ} 17$, pp. 11-30

ARIZA SEGUÍN, M. (2005): «Las zonas de montaña y las políticas europeas» en El futuro de las montañas en la Unión Europea del siglo XXI, Barcelona, 14-16 de septiembre de 2005, http:// www.ctp.org/comun/novedades/2005/CongresoFuturo/ponencias/Ponencia3.pdf

BORJABAD GONZALO, P. (1993): «Legislación comunitaria para áreas deprimidas de montaña: legislación del estado español», en Geórgica. Revista del espacio rural, 1 (extra): pp. 37-46.

CABERO DIÉGUEZ, V., MAJORAL MOLINÉ, R. y RODRÍGUEZ MARTÍNEZ, F. (1992): «Las áreas de montaña y su problemática» en La Geografía en España (1970-1990). Aportación española al XXVII Congreso Internacional de la UGI (Washington, 1992), Real Sociedad Geográfica, Asociación de Geógrafos Españoles y Fundación BBV. Madrid. pp. 247-261.

CIMA (Colectivo de Investigadores sobre las Montañas Españolas) (2005a): Las Montañas Españolas: Territorio, Sociedad, Patrimonio y Cultura. Ministerio de Ciencia y Tecnología, http://www. lasmontanasespanolas.com/ y http://www.ub.edu/montesp/.

CIMA (Colectivo de Investigadores sobre las Montañas Españolas) (2005b): Las Montañas Españolas: Conceptos y Vocabulario. Entinema, Madrid.

COLLANTES GUTIÉRREZ, F. (2004): El declive demográfico de la montaña española (18502000): ¿un drama rural?. Ministerio de Agricultura, Pesca y Alimentación (Serie Estudios, $\mathrm{n}^{\circ}$ 159), Madrid.

COMISIÓN EUROPEA (2000): Las políticas estructurales y los territorios de Europa: la montaña. Oficina de Publicaciones Oficiales de la Comisión Europea (OPOCE). Luxemburgo.

DELGADO SERRANO, Ma M. (2004): La política rural europea en la encrucijada. MAPA, Madrid.

DELGADO VIÑAS, C. (Ed.) (2006a): La Montaña Cantábrica, una montaña viva. Servicio de Publicaciones de la Universidad de Cantabria, Santander.

DELGADO VIÑAS, C. (2006b): «Las políticas aplicadas en Europa a las áreas de montaña: una síntesis y algunas reflexiones» en Las agriculturas españolas y la política agraria comunitaria: 20 años después. Actas del XIII Coloquio de Geografía Rural. Baeza, 4-6 de octubre de 2006. Baeza. pp. 342-357.

DELGADO VIÑAS, C. (2006c): «Ordenación del territorio y desarrollo sostenible en áreas de montaña: diagnóstico y propuestas para la integración productiva y territorial de Los Montes de Pas (Cantabria)» en Boletín de la Asociación de Geógrafos Españoles, n 42, pp. 53-70.

FERNÁNDEZ ARROYO, R., GONZÁLEZ, J.L., ALONSO, E. y ÁLVAREZ, G. (2005): «La carta española de las montañas. Perspectiva y desarrollo de los trabajos realizados» en El futuro de las montañas en la Unión Europea del siglo XXI, Barcelona, 14-16 de septiembre de 2005, http://www.ctp.org/comun/novedades/2005/CongresoFuturo/ponencias/Ponencia18.pdf 
GARCÍA PASCUAL, F. (2006): «Políticas públicas y sustentabilidad en las zonas desfavorecidas y de montaña» en Boletín de la AGE, no 41, pp. 151-182.

GARCÍA-RUIZ, J.M ${ }^{\mathrm{a}}$. (1988): «La evolución de la agricultura de montaña y sus efectos sobre la dinámica del paisaje» en Revista de Estudios Agrosociales, n 146, pp. 7-37.

GÓMEZ BENITO et alii (1987): La política socioestructural en zonas de agricultura de montańa en España y en la CEE». Ed: Secretaría General Técnica del MAPA. Madrid.

GÓMEZ MENDOZA, J. (1995): «Desarrollo rural y espacios naturales protegidos», en RAMOS LEAL, E. y CRUZ VILLALÓN, J. (Coords.): Hacia un nuevo sistema rural, Madrid. MAPA, Secretaría General Técnica, Serie «Estudios» n ${ }^{\circ}$ 99, pp. 381-410.

GONZÁLEZ FERNÁNDEZ, M. (2005): «Desarrollo rural en zonas de montaña. Más allá de las políticas europeas» en Unión de Pequeños Agricultores (UPA): Agricultura Familiar en España 2005, pp. 159-164, http://www.upa.es/anuario 2005/index.htm .

IZQUIERDO, J. (2006): «Desarrollo sostenible en zonas de montaña», http://www.readerasturias. org/.

LAGUNA MARÍN-YASELI, M. (2001-2002): «Políticas de desarrollo en el medio rural: una visión de la legislación de la Unión Europea» en Polígonos. Revista de Geografía, n 11-12, pp. 219233.

LLORENTE PINTO, J.M. (2003): «Bilan des transformations dans les zones de montagne espagnoles» en CERAMAC: Crisis et mutations des agricultures de montagne, Colloque international en homage au Professeur Christian Mignon. Clermont-Ferrand, pp.675-690.

MAIRAL LACOMA, J.A. (1993): «La Política de desarrollo de las zonas desfavorecidas y de montaña en la Comunidad Europea» en Revista de derecho agrario y alimentario, $\mathrm{n}^{\circ}$ 21-22, 1993, pp. 44-48.

MAITİA, F. (2006): «La montaña en la Unión Europea: políticas y proyectos» en DELGADO VIÑAS, C. (Ed.): La Montaña Cantábrica, una montaña viva, Servicio de Publicaciones de la Universidad de Cantabria, Santander.

MAJORAL MOLINÉ, R. (1997): «Desarrollo en áreas de montaña» en Geographicalia, nº 34, pp. 23-49.

MARTÍN JIMÉNEZ, M ${ }^{\mathrm{a}}$ I. (2002): «La ordenación del territorio y las zonas de montaña. Evolución en el contexto de la Unión Europea» VV.AA.: Los espacios rurales entre el hoy y el mañana. XI Coloquio de Geografía Rural. Universidad de Cantabria/AGE, Santander, pp. 719-727.

MARTÍN JIMÉNEZ, M I I. (2005): «Retos y oportunidades de las comarcas de montaña abulenses» en Estudios Geográficos, n ${ }^{\circ} 258$, pp. 161-185.

MARTÍNEZ DE PISÓN, E. (2000): «Imagen de la naturaleza de las montañas», en MARTÍNEZ DE PISÓN, E. (Dir.): Estudios sobre el paisaje, UAM/Ediciones y Fundación Duques de Soria (Colección de Estudios, no 67), Murcia, pp. 15-54.

MINISTERIO DE AGRICULTURA, PESCA Y ALIMENTACIÓN (M.A.P.A.) (1987): La política socioestructural en zonas de agricultura de montaña en España y la CEE. Secretaría General Técnica, Madrid.

MOSCOSO SÁNCHEZ, D. J. (2005): «Desarrollo rural en zonas de montaña» en Agricultura Familiar en España, pp. 148-157

NORDREGIO (NORDIC CENTRE FOR SPATIAL DEVELOPMENT) : Zones de montagne en Europe: analyse des régions de montagne dans les États membres actuels, les nouveaux États membres et d'autres pays européens. Informe Final (Enero de 2004) encargado por la Comisión Europea (2002, CE.16.0.AT.136) http://www.europa.eu.int/comm/regional_policy/sources/docgener/studies/study fr.htm

ORTUÑO PÉREZ, S.F. y ZAMORA, R. (2001): «Las áreas de montaña y los nuevos modelos de desarrollo rural» en Revista española de estudios agrosociales y pesqueros, $\mathrm{n}^{\circ} 191, \mathrm{pp}$. 41-60.

PLAZA GUTIÉRREZ, J.I. (2006): «Territorio, Geografía Rural y Políticas Públicas. Desarrollo y Sustentabilidad en las áreas rurales» en Boletín de la AGE, n ${ }^{\circ}$ 41, pp. 69-95.

REQUENA SÁNCHEZ, M.D. (1996): «Bases comunitarias para el desarrollo rural en zonas de montaña» en Actas del VIII Coloquio de Geografía Rural. Universidad de Zaragoza-AGE/Departamento de Geografía y Ordenación del Territorio pp. 339-348. 
RIVERA MATEOS, M. (1987): «Recopilación bibliográfica sobre sistemas agrarios, gestión de recursos y desarrollo rural en la montaña española. Guía y revisión bibliográfica para su estudio» en Revista de Estudios Agro-Sociales, $\mathrm{n}^{\circ}$ 142, pp. 217-272.

RODRÍGUEZ BLANCO, Julián (2003), «Ayer y hoy en la agricultura de montaña. La necesidad de un trato especial», LEADER. Revista de Desarrollo Rural, n 22, pp. 20-22.

RODRÍGUEZ GUTIÉRREZ, F. (1990): «Las políticas agrarias: agricultura de montaña» en Los espacios rurales cantábricos y su evolución. Universidad de Cantabria/Asamblea Regional de Cantabria. Santander, pp. 136-153.

RODRÍGUEZ GUTIÉRREZ, F. (1993): «El balance de un decenio de política de montaña en España (1982-1992)» en Ería: Revista cuatrimestral de geografía, $n^{\circ}$ 30, pp. 61-72.

RODRÍGUEZ GUTIÉRREZ, F. (1994): «Las estrategias de aplicación de la política de montaña en las comunidades autónomas atlánticas españolas» en VV.AA.: El medio rural español: cultura, paisaje y naturaleza: homenaje a don Ángel Cabo Alonso. Salamanca, Universidad de Salamanca, Vol. 2, pp. 1089-1099

RODRÍGUEZ MARTÍNEZ, F. (2001): «Las montañas andaluzas en la encrucijada del desarrollo rural» en Ería, no 54-55, pp. 125-140.

SÁNCHEZ SÁNCHEZ, J. (1993): «Las áreas de montaña en España: crisis reciente y políticas de desarrollo» en II Seminario Hispano-Húngaro sobre Desequilibrios Regionales, UNED e Instituto de Estudios Regionales de la Academia de Ciencias de Hungría, Madrid, pp. 77-96.

SÁNCHEZ SÁNCHEZ, J. (1995): «La política de desarrollo rural en áreas de montaña: de la visión sectorial al enfoque integrado» en A.G.E.: Actas del XIV Congreso Nacional de Geografía, Salamanca, pp. 224-227.

SANZ TOLOSANA, E. (2005): «Tendencias de las políticas de montaña europeas: nuevos retos y desafíos» en Inguruak: Revista vasca de sociología y ciencia política, $\mathrm{n}^{\circ} 41$, pp. 175-189.

SUMPSI VIÑAS, J.Ma . (1996): «El enfoque territorial de la política agraria europea y su impacto en el desarrollo regional» en XXII Reunión de Estudios Regionales. El desarrollo de las regiones: nuevos escenarios y nuevas perspectivas de análisis, Ponencias. Universidad Pública de Navarra y Asociación de Ciencia Regional del País Vasco y Navarra, Pamplona, pp. 161-179.

TROITIÑO VINUESA, M.A. et al. (2006): «La experiencia del Patronato Madrileño de Áreas de Montaña (PAMAM) como estrategia de cooperación y desarrollo sostenible en la Sierra Norte de Madrid» en ROMERO, J. y FARINÓS, J. (Eds.): Gobernanza territorial en España. Claroscuros de un proceso a partir del estudio de casos, Publicacions de la Universitat de Valencia, Valencia, pp. 327-346.

VELÁZQUEZ, L.R. (2003): «Las zonas de montaña en LEADER II y PRODER. un factor de oportunidad» en LEADER. Revista de Desarrollo Rural, $\mathrm{n}^{\circ}$ 22, pp. 23-27.

VILLENEUVE, A., CASTELEIN, A. y MEKOUAR, M.A. (2003): Las montañas y el derecho. Tendencias actuales. Organización de las Naciones Unidas para la Agricultura y la Alimentación (FAO)-Estudio Legislativo, $\mathrm{n}^{\circ}$ 75, Roma, $100 \mathrm{pp}$.

VV.AA. (1992): La Montaña en los 90. El Campo. Boletín de Información Agraria, Servicio de Estudios del BBV. Bilbao.

VV.AA. (1997): Paisaje y desarrollo integral en áreas de montaña, VII Jornadas sobre el Paisaje, (Segovia 17-21 de octubre de 1994), Ministerio de Medio Ambiente, Madrid. 